\title{
Case Report \\ Seronegative Myasthenia Gravis, as a Rare Autoimmune Condition in Turner Syndrome
}

\author{
Rimah Sharief, Amir Miodovnik, and Roja Motaghedi \\ Infant and Children's Hospital of Brooklyn, Maimonides Medical Center, 977 48th Street, Brooklyn, NY 11219, USA \\ Correspondence should be addressed to Roja Motaghedi; rmotaghedi@maimonidesmed.org
}

Received 22 July 2017; Accepted 22 October 2017; Published 14 November 2017

Academic Editor: Piero Pavone

Copyright (C) 2017 Rimah Sharief et al. This is an open access article distributed under the Creative Commons Attribution License, which permits unrestricted use, distribution, and reproduction in any medium, provided the original work is properly cited.

Girls with Turner syndrome (TS), especially with isochromosome 46,X,i(X)(q10), are prone to develop autoimmunity. Associations of several autoimmune conditions with TS have been frequently described in the past. However, the unique combination of TS and myasthenia gravis (MG) has been reported only once before in a girl with mosaic monosomy 45,X/46,XX. Here, we present the second case of a girl affected with seronegative MG but with mosaic isochromosome TS. This is a child with developmental delay presented with muscle weakness, frequent fall, and bilateral ptosis. Diagnosis of MG was made based on positive Tensilon and electromyography tests and excellent response to intravenous immunoglobulin. At the age of 11 years due to short stature and developmental delay, a karyotype was done and revealed the mosaic isochromosome $45, \mathrm{X} / 46, \mathrm{X}, \mathrm{i}(\mathrm{X})(\mathrm{q} 10)$. Overall, clinicians should be aware of the vulnerability of girls with TS to autoimmunity, especially if the isochromosome $46, \mathrm{X}, \mathrm{i}(\mathrm{X})$ (q10) karyotype is identified. Furthermore, if a child with TS develops muscle weakness, ptosis, or ophthalmoplegia, MG should also be included in the differential diagnosis, particularly if other concurrent autoimmune conditions are present.

\section{Introduction}

Turner syndrome (TS) is caused by total or partial loss or defect of the female second sex chromosome (X) [1]. The reported incidence is approximately 1 in 2000-2500 live births $[2,3]$, and 1 in 60 cases of female with short stature are affected with TS [2]. Monosomy X $(45, \mathrm{X})$ is the most common overall karyotype, encountered in approximately $45 \%$ of diagnosed cases, whereas the most common $\mathrm{X}$ chromosome structural defect is the isochromosome $46, \mathrm{X}, \mathrm{i}(\mathrm{X})(\mathrm{q} 10)$ that comprises approximately $15-18 \%$ of total cases of TS [3].

The isochromosome $46, \mathrm{X}, \mathrm{i}(\mathrm{X})$ (q10) is a duplication of the long arm of the $\mathrm{X}$ chromosome, fused at the head with a missing short arm [4]. Other less common structural abnormalities include ring chromosome $(r)$ and deletion of Xp or Xq; both could present as mosaic with another cell line. The structurally defective chromosomes are believed to be fetoprotective, compared to the $45, \mathrm{X}$ karyotype that explains the higher ratio of $46, \mathrm{X}, \mathrm{i}(\mathrm{X})(\mathrm{q} 10)$ and $46, \mathrm{X} / \mathrm{r}(\mathrm{X})$ fetuses who are diagnosed as pregnancy advances to term [5].
Depending on the degree of the mosaicism and its timing during development, girls with TS have a series of phenotypic features with various severity [2], most notably short stature and gonadal dysgenesis [1]. Other features include but are not limited to cognitive deficits, skeletal deformities, cardiovascular diseases, hearing difficulties, renal anomalies, and a high propensity to develop an autoimmune condition that is the focus of this report [6].

All girls with various forms of Turner syndrome are at risk for autoimmunity [6], but females with $46, \mathrm{X}, \mathrm{i}(\mathrm{X})(\mathrm{q} 10)$ are specifically at a higher risk [7-10]. The most common autoimmune association is thyroiditis, often in the form of Hashimoto's thyroiditis [7-10], but Graves' disease can also be seen [11]. Elsheikh et al. [10] have reported that approximately $83 \%$ of females with $46, \mathrm{X}, \mathrm{i}(\mathrm{X})(\mathrm{q} 10)$ have autoimmune thyroiditis, compared to $45 \%$ of females with monosomy X and $24 \%$ with mosaic TS. Association of other autoimmune conditions has been summarized in Table 1 and includes celiac disease (CD), inflammatory bowel disease (IBD), and type 1 diabetes mellitus (T1DM) [7, 9, 12]. Vitiligo, alopecia areata, psoriasis [9], primary biliary cirrhosis [13], systemic 
TABLE 1: Estimated prevalence of autoimmunity in Turner syndrome.

\begin{tabular}{|c|c|c|}
\hline Autoimmunity & Prevalence in TS (\% of diagnosed cases) & Author, year (ref.) \\
\hline Hashimoto's thyroiditis & $30-60$ & Elsheikh et al., 2001 [10] \\
\hline Celiac disease & $2.7-17$ & $\begin{array}{l}\text { Bakalov and Gutin, } 2012 \text { [9] } \\
\text { Mortensen et al., 2009 [12] }\end{array}$ \\
\hline IBD & 4 & Bakalov and Gutin, 2012 [9] \\
\hline Type 1 diabetes mellitus & $0.9-4$ & $\begin{array}{l}\text { Bakalov and Gutin, } 2012 \text { [9] } \\
\text { Mortensen et al., 2009 [12] }\end{array}$ \\
\hline Psoriasis & 3.1 & Bakalov and Gutin, 2012 [9] \\
\hline Graves' disease & $0.7-2.7$ & $\begin{array}{l}\text { Elsheikh et al., } 2001[10] \\
\text { Valenzise et al., } 2014 \text { [11] }\end{array}$ \\
\hline Adrenal antibodies & $1-2$ & $\begin{array}{c}\text { Hamza et al., } 2013 \text { [8] } \\
\text { Mortensen et al., } 2009 \text { [12] }\end{array}$ \\
\hline JRA and RA & 0.9 & Bakalov and Gutin, 2012 [9] \\
\hline Ankylosing spondylitis & 0.4 & Bakalov and Gutin, 2012 [9] \\
\hline
\end{tabular}

IBD: inflammatory bowel disease; JRA: juvenile rheumatoid arthritis; RA: rheumatoid arthritis.

TABle 2: Clinical characteristics of our patient compared to the first reported case of TS affected with MG.

\begin{tabular}{|c|c|c|}
\hline Clinical characteristics & Our index case & First published case ${ }^{1}$ (Chen et al., 1978) [17] \\
\hline Age at MG onset & 6 years & 15 years \\
\hline Age of TS diagnosis & 10 years & 10 years \\
\hline Ethnicity & African American & Caucasian \\
\hline Genetic defects (TS karyotype) & $45, \mathrm{X} / 46, \mathrm{X}, \mathrm{i}(\mathrm{X})(\mathrm{q} 10)$ & $45, \mathrm{X} / 46, \mathrm{XX}$ \\
\hline MG symptoms & $\begin{array}{l}\text { Left eye ptosis }(+) \text {, ophthalmoplegia }(-) \\
\text { Frequent fall }(+) \text {, fatigue }(+)\end{array}$ & $\begin{array}{l}\text { Bilateral ptosis }(+) \text {, ophthalmoplegia }(+) \\
\text { Frequent fall }(+), \text { fatigue }(+)\end{array}$ \\
\hline Serology & Negative AChR, MuSK, and $\alpha-S M$ Abs & $\begin{array}{l}\text { AChR Abs and MuSK not performed. Negative } \\
\text { a-SM Abs }\end{array}$ \\
\hline Tensilon test and EMG & Positive & Positive \\
\hline Thyroid autoimmunity & $\begin{array}{l}\alpha-\mathrm{TPO}(+) \text { and } \alpha-\operatorname{Tg}(+) \\
\text { Euthyroid up to this point }\end{array}$ & $\begin{array}{c}\alpha-\operatorname{TPO}(+) \text { and } \alpha-\operatorname{Tg}(+) \\
\text { Developed hypothyroid at the age of } 15 y\end{array}$ \\
\hline Other antibody screening & $\begin{array}{c}\text { Positive: } \alpha-G A D-65 \\
\text { Negative: AGA, ASMA, } \alpha \text {-SM Ab, ANA, } \alpha \text {-dsDNA, } \\
\text { a-ssDNA, } \alpha \text {-MPO, proteinase-3, } \alpha \text {-adrenal Abs, direct } \\
\text { a-globulin Abs }\end{array}$ & $\begin{array}{c}\text { Positive: ASMA, } \alpha \text {-myelin Ab } \\
\text { Negative: } \alpha \text {-DNA Ab, } \alpha \text {-adrenal Ab, } \alpha-\text { Coomb }^{2} \mathrm{Ab}\end{array}$ \\
\hline Initial treatment & $\begin{array}{l}\text { Cholinesterase inhibitors and glucocorticoid with } \\
\text { no response }\end{array}$ & Cholinesterase inhibitors with no response \\
\hline Definitive treatment & Periodic IVIG infusion & Thymectomy followed by cholinesterase inhibitors \\
\hline
\end{tabular}

sclerosis [14], and autoimmune hypophysitis [15] have rarely been reported in girls with TS as well. Even some of the predominantly male-dominant autoimmune conditions, such as Dupuytren's contracture and ankylosing spondylitis, seem to be more common in girls with TS (with about fivefold increase in girls with $46, \mathrm{X}, \mathrm{i}(\mathrm{X})(\mathrm{q} 10)$ karyotype, compared to unaffected females) [16].

Myasthenia gravis (MG) has been documented only once before in a 15-year-old girl with Turner syndrome and 45,X/46,XX karyotype [17]. Here, we present a second case affected with MG but with a mosaic $45, \mathrm{X} / 46, \mathrm{X}, \mathrm{i}(\mathrm{X})$ (q10) Turner syndrome. Clinical comparison of the first case to our patient with respect to MG is presented in Table 2.

\section{Clinical Presentation}

Our patient is a 10-year-old girl of Jamaican descent, a product of nonconsanguineous marriage, who was born premature at 32 weeks of gestation with a birth weight of $4 \mathrm{lb} 4 \mathrm{oz} / 1.928 \mathrm{~kg}$ (appropriate for gestational age). Developmental delays and learning difficulties were noted at an early age, requiring intense special education with placement in small, self-contained classroom at the kindergarten level.

At the age of 6 years, she experienced unilateral (left) droopy eyelid and frequent falls, associated with generalized fatigue. Neurological evaluation revealed negative acetylcholine receptor binding and blocking antibodies (AChR-Abs) and muscle-specific kinase antibodies (MuSK-Abs). However, 
Tensilon test (TT) and electromyography (EMG) were both suggestive of generalized MG, excluding the congenital myasthenic syndromes and other conditions mimicking MG. Diagnosis of seronegative MG was initially considered based on the findings from TT and EMG and, subsequently, confirmed by excellent response to periodic intravenous immunoglobulin (IVIG) infusion ( $1 \mathrm{~g} / \mathrm{kg}$ infusion on 2 consecutive days every 4 weeks). In fact, the IVIG was initially administered at every 5th weekly interval, but her symptoms recurred towards the end of the 4 th week. This prompted the change of the frequency to every 4 th week with significant improvement of droopy eyelid, excessive fatigue, and frequent fall.

At the age of 10 years and 4 months, due to growth deceleration and significant developmental issues, she had a formal multidisciplinary evaluation by a pediatric developmental specialist and an endocrinologist. During the initial endocrine evaluation, she was noted to be short with a height at the 3rd percentile for age and sex, as compared to her midparental height of the 75th percentile. Her physical features were only mildly consistent with TS that likely contributed to delayed diagnosis up to that point. She was noted to have an oblong face with mild facial dysmorphism, down-slanting eyes, bushy eyebrows, low hairline, bilateral in toeing, and her left nipple noted to be laterally displaced. Madelung deformity was not present. In terms of puberty, she had pubic hair development at Tanner stage 2 without thelarche, and biochemically, she was prepubertal (FSH: $8.4 \mathrm{mlU} / \mathrm{ml}(8.4 \mathrm{IU} / \mathrm{L}), \mathrm{LH}<0.2 \mathrm{mlU} / \mathrm{ml}(<0.2 \mathrm{IU} / \mathrm{L})$, and E2 $<15(<4.086 \mathrm{pmol} / \mathrm{L}))$.

Formal developmental evaluation revealed global delays in cognitive, social, adaptive, and motor skills. She was in the 3rd grade but performing well below the grade level. While she was friendly and cooperative during examination, her social interactions appeared immature for her age. There were also concerns regarding hyperactivity, poor concentration, and distractibility, and she met diagnostic criteria for attention-deficit/hyperactivity disorder (ADHD). Overall, her cognitive profile was consistent with other girls who have Turner syndrome (TS). Girls with TS often show selective impairment in nonverbal skills relative to verbal domains on standardized intelligence tests. In addition, they frequently display more difficulty with problem-solving tasks (e.g., mathematics), visuospatial awareness (e.g., difficulty with direction sense), and slower processing speed, with higher rates of ADHD than in the general population [18].

Given her intellectual impairments, short stature, and a mild dysmorphic feature, a genetic workup was carried out. Karyotype with 30 cell counts revealed mosaic Turner syndrome with isochromosome $45, \mathrm{X}$ (23 cells)/46,X,i(X) (q10) (7 cells). In addition, the CGH microarray analysis confirmed the 45,X/46,X,i(X)(q10) karyotype and showed a duplication of $311.5 \mathrm{~kb}$ on the chromosome $6 \mathrm{q} 22.33$ that seemed to be maternally inherited but of no clinical significance. This diagnosis subsequently triggered cardiac, audiology, and kidney evaluations. A cardiac murmur was present, but echocardiographic examination did not reveal any structural abnormality. Hearing testing was normal initially, but repeated evaluations revealed mild left ear conductive hearing loss. Furthermore, renal ultrasound showed a mild increase in echogenicity in both kidneys, without any functional impairment or significant structural defect. Persistent asymptomatic nonimmune transaminitis and leukopenia, commonly seen in Turner syndrome, were also noted.

Since autoimmunity is common in Turner syndrome and our patient was already affected with MG, we carried out an extensive antibody screening that revealed positive antithyroperoxidase antibodies ( $\alpha$-TPO), anti-thyroglobulin antibodies $(\alpha-\mathrm{Tg})$, and anti-glutamic acid decarboxylase-65 antibodies (GAD-65 Ab). Of note, GAD-65 is one of the 2 isoenzymes of GAD that is present in pancreatic islet cells and nerve cell terminals and synapses. In the nervous system, GAD-65 is involved in synthesis and release of $\gamma$-aminobutyric acid (GABA), which is the main CNS inhibitory neurotransmitter. GAD-65 positivity has been linked to many CNS disorders such as immune-mediated cerebellar ataxia (IMCA), refractory seizures, and stiff person syndrome (SPS) besides type 1diabetes mellitus (T1DM) [19]. Clinical characteristics of our patient with a complete list of antibodies screened are provided in Table 2.

As presented, our patient and previously reported case by Chen et al. [17] were both diagnosed with autoimmune thyroiditis, but unlike the first case, our patient has remained euthyroid up to this point. Also, the case reported by Chen et al. carried a mosaic $45, \mathrm{X} / 46, \mathrm{XX}$ karyotype, while our patient is a mosaic $45, \mathrm{X} / 46, \mathrm{X}, \mathrm{i}(\mathrm{X})$ (q10) with negative MGrelated antibodies.

2.1. Follow-Ups and Interventions. The thyroid function test has been normal up to this point. As mentioned above, she received periodic IVIG infusion for MG with good control.

In terms of neurodevelopmental intervention, she receives intense therapy and special education. For her height, she was immediately started on growth hormone at the dose of $0.35 \mathrm{mg} / \mathrm{kg} /$ week and eventually increased to $0.37 \mathrm{mg} / \mathrm{kg} /$ week. We plan to start estrogen replacement at the age of 12 years.

\section{Conclusions and Discussion}

MG has been reported only once before [17] in TS, and our patient is the second case (Table 2). As noted above, our case did not test positive for MG-related antibodies and was diagnosed based on clinical findings and response to treatment. However, it is known that autoantibodies (AChR antibodies or MuSK antibodies) could be absent in 10-20\% of established cases of MG [20], in this case also known as double seronegative MG. However, the seronegative MG is also an autoimmune condition, but lack of antibody positivity is presumed to be due to an insensitivity of the commercial assay to detect antibodies or presence of antibodies towards other antigen particles [20], in the neuromuscular junction, such as cortactin antibodies [21], low-density lipoprotein receptorrelated protein 4 (Lrp4) [22], and anti-striated muscle antibodies $(\alpha-S M)$ not measured by the commercial assay.

It is very well known that children with Turner syndrome, especially TS with $46, \mathrm{X}, \mathrm{i}(\mathrm{X})(\mathrm{q} 10)$, are at high risk of developing autoimmunity with thyroid being the most 
common target of immune response. The significant tendency of females with TS to develop autoimmunity is not fully understood but presumed to be due to the lack or abnormality of the second X chromosome (X chromosome haploinsufficiency), especially $\mathrm{Xp}$ monosomy, which subsequently results in abnormal T-cell regulatory function and inability to develop self-tolerance in early life [9]. In addition, a dysregulation of immune response with shift to proinflammatory cytokine response (IL6 and TGF $\beta 2$ ) and decrease in the anti-inflammatory cytokines (IL10 and TGF $\beta 1$ ) has also been observed in females with TS and postulated to play a role in tendency to develop self-antibody [9].

In conclusion, clinicians need to be aware of this propensity and have high index of suspicion for a range of autoimmune conditions, especially when the genetic defect is isochromosome $46, \mathrm{X}, \mathrm{i}(\mathrm{X})(\mathrm{q} 10)$. Furthermore, myasthenia gravis should be in mind, when a child with Turner syndrome presents with muscle weakness, droopy eyelid, or ophthalmoplegia, even though an isolated ptosis is also a known feature of girls with TS [6].

\section{Abbreviations}

TS: $\quad$ Turner syndrome

46,X,i $(\mathrm{X})(\mathrm{q} 10)$ : Isochromosome Xq

MG: Myasthenia gravis

AChR-Abs: Acetylcholine receptor antibodies

a-GAD-65: Anti-glutamic acid decarboxylase-65.

\section{Consent}

Informed consent was obtained before writing this article.

\section{Conflicts of Interest}

All authors declare no conflicts of interest relevant to this article to disclose.

\section{References}

[1] M. A. Ferguson-Smith, "Karyotype-phenotype correlations in gonadal dysgenesis and their bearing on the pathogenesis of malformations," Journal of Medical Genetics, vol. 2, no. 2, pp. 142-155, 1965.

[2] B. Lippe, "Primary ovarian failure," Clinical Pediatric Endocrinology, vol. 2, pp. 325-365, 1990.

[3] D. J. Wolff, D. L. van Dyke, and C. M. Powell, "Laboratory guideline for Turner syndrome," Genetics in Medicine, vol. 12, no. 1, pp. 52-55, 2010.

[4] I. Haltrich, H. Pikó, H. Pamjav et al., "Complex X chromosome rearrangement associated with multiorgan autoimmunity," Molecular Cytogenetics, vol. 8, no. 1, p. 51, 2015.

[5] E. B. Hook and D. Warburton, "The distribution of chromosomal genotypes associated with Turner's syndrome: livebirth prevalence rates and evidence for diminished fetal mortality and severity in genotypes associated with structural X abnormalities or mosaicism," Human Genetics, vol. 64, no. 1, pp. 24-27, 1983.

[6] D. Larizza, V. Calcaterra, and M. Martinetti, "Autoimmune stigmata in Turner syndrome: when lacks an X chromosome," Journal of Autoimmunity, vol. 33, no. 1, pp. 25-30, 2009.
[7] A. Grossi, A. Crinò, R. Luciano, A. Lombardo, M. Cappa, and A. Fierabracci, "Endocrine autoimmunity in Turner syndrome," Italian Journal of Pediatrics, vol. 39, no. 1, p. 79, 2013.

[8] R. T. Hamza, N. A. Raof, and K. O. Abdallah, "Prevalence of multiple forms of autoimmunity in Egyptian patients with Turner syndrome: relation to karyotype," Journal of Pediatric Endocrinology and Metabolism, vol. 26, no. 5-6, pp. 545-550, 2013.

[9] V. K. Bakalov, L. Gutin, C. M. Cheng et al., "Autoimmune disorders in women with turner syndrome and women with karyotypically normal primary ovarian insufficiency," Journal of Autoimmunity, vol. 38, no. 4, pp. 315-321, 2012.

[10] M. Elsheikh, J. A. Wass, and G. S. Conway, "Autoimmune thyroid syndrome in women with Turner's syndrome-the association with karyotype," Clinical Endocrinology, vol. 55, no. 2, pp. 223-226, 2001.

[11] M. Valenzise, T. Aversa, A. Corrias et al., "Epidemiology, presentation and long-term evolution of Graves' disease in children, adolescents and young adults with Turner syndrome," Hormone Research in Paediatrics, vol. 81, no. 4, pp. 245-250, 2014.

[12] K. H. Mortensen, L. Cleemann, B. E. Hjerrild et al., "Increased prevalence of autoimmunity in Turner syndrome-influence of age," Clinical \& Experimental Immunology, vol. 156, no. 2, pp. 205-210, 2009.

[13] I. Bianchi, A. Lleo, F. Bernuzzi, L. Caliari, D. S. Smyk, and P. Invernizzi, "The X-factor in primary biliary cirrhosis: monosomy X and xenobiotics," Autoimmunity Highlights, vol. 3, no. 3, pp. 127-132, 2012.

[14] P. Invernizzi, M. Miozzo, C. Selmi et al., "X chromosome monosomy: a common mechanism for autoimmune diseases," Journal of Immunology, vol. 175, no. 1, pp. 575-578, 2005.

[15] A. J. Pollock, T. S. Seibert, C. Salvatori, P. Caturegli, and D. B. Allen, "Pituitary antibodies in an adolescent with secondary adrenal insufficiency and Turner syndrome," Hormone Research in Paediatrics, vol. 87, no. 2, pp. 123-129, 2017.

[16] K. T. Jorgensen, K. Rostgaard, I. Bache et al., "Autoimmune diseases in women with Turner's syndrome," Arthritis \& Rheumatism, vol. 62, no. 3, pp. 658-666, 2010.

[17] H. Chen, W. H. Hoffman, C. H. Chang, Z. Hart, and J. Kaplan, "Lymphocytic thyroiditis, myasthenia gravis and Turner syndrome," Birth Defects Original Article Series, vol. 14, no. 6A, pp. 137-147, 1978.

[18] C. A. Bondy, "Care of girls and women with Turner syndrome: a guideline of the Turner Syndrome Study Group," Journal of Clinical Endocrinology \& Metabolism, vol. 92, no. 1, pp. 10-25, 2007.

[19] H. Mitoma, K. Adhikari, D. Aeschlimann et al., "Consensus paper: neuroimmune mechanisms of cerebellar ataxias," Cerebellum, vol. 15, no. 2, pp. 213-232, 2016.

[20] H. J. Kaminski, "Seronegative myasthenia gravis-a vanishing disorder?," JAMA Neurology, vol. 73, no. 9, pp. 1055-1056, 2016.

[21] E. Cortés-Vicente, E. Gallardo, M. Ángeles Martínez et al., "Clinical characteristics of patients with double-seronegative myasthenia gravis and antibodies to Cortactin," JAMA Neurology, vol. 73, no. 9, pp. 1099-1104, 2016.

[22] O. Higuchi, J. Hamuro, M. Motomura, and Y. Yamanashi, "Autoantibodies to low-density lipoprotein receptor-related protein 4 in myasthenia gravis," Annals of Neurology, vol. 69, no. 2, pp. 418-422, 2011. 


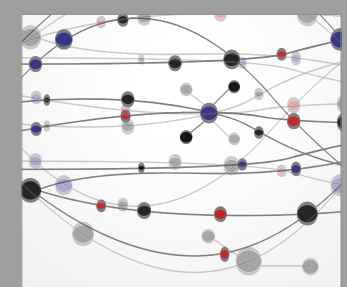

The Scientific World Journal
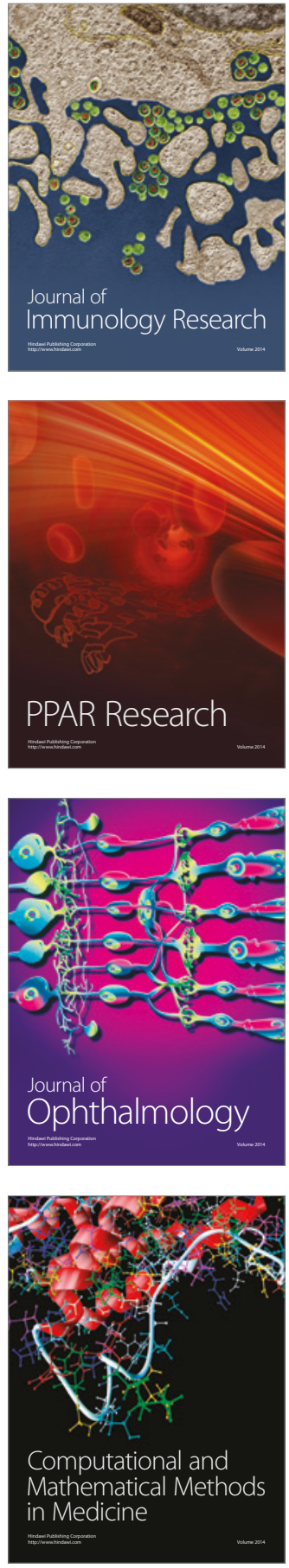

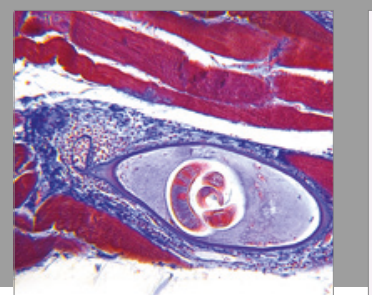

Gastroenterology Research and Practice
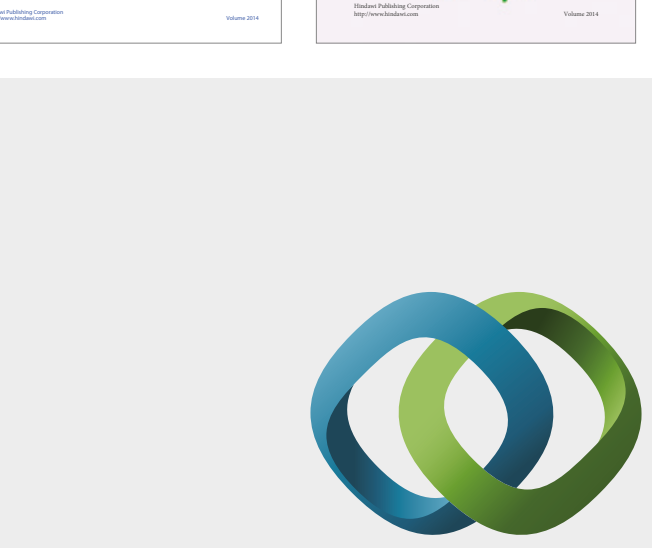

\section{Hindawi}

Submit your manuscripts at

https://www.hindawi.com
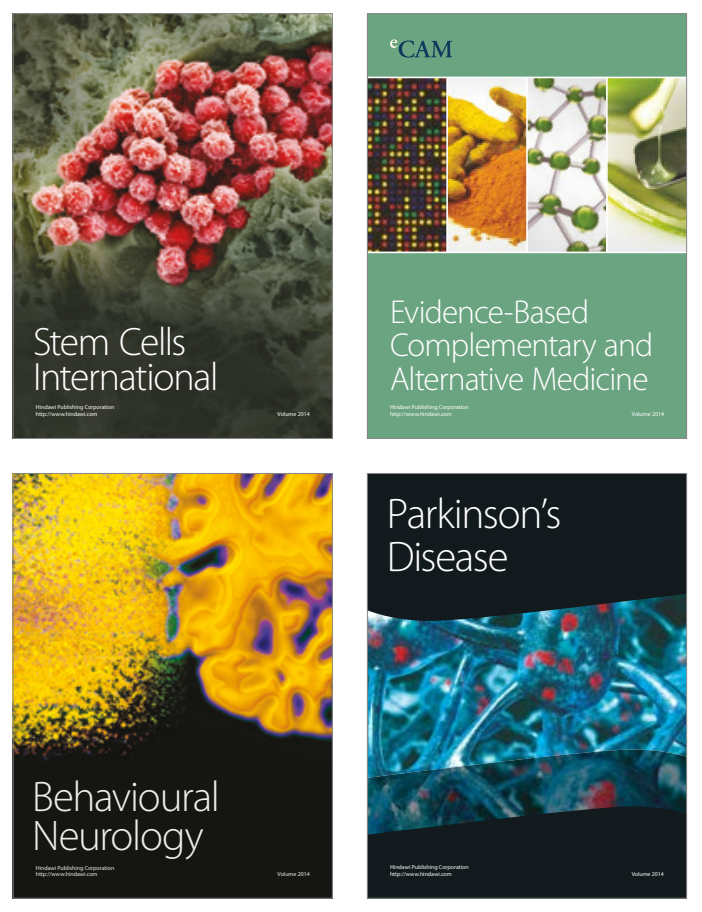
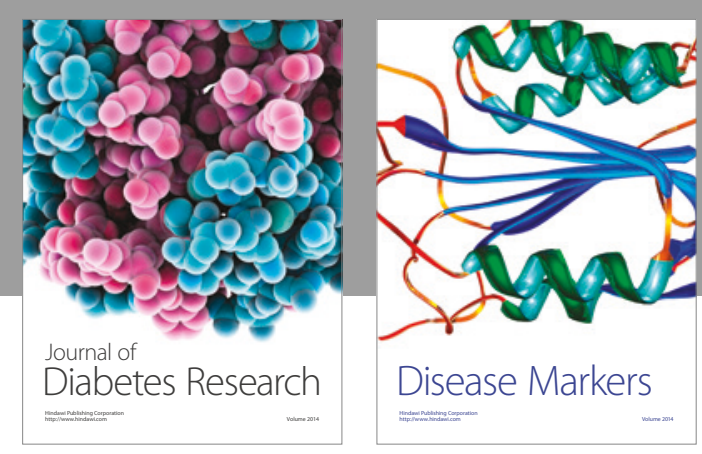

Disease Markers
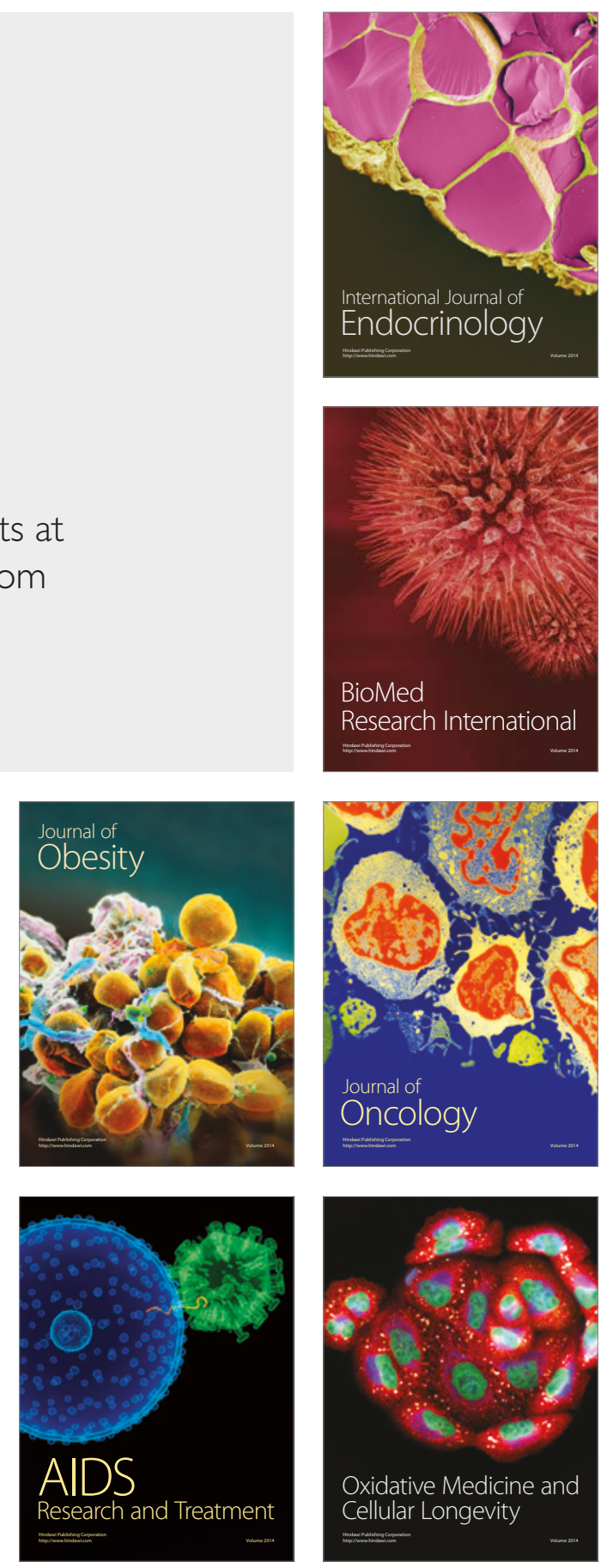